\title{
CORRECTION
}

Open Access

\section{Correction to: Preliminary evaluation of the Vision PERformance (VIPER) simulator}

Denise S. Ryan ${ }^{1 *}$, Rose K. Sia ${ }^{1}$, Jennifer B. Eaddy ${ }^{1}$, Lorie A. Logan' ${ }^{1}$ Jide O. Familoni ${ }^{2}$, Hind Beydoun ${ }^{3}$, Samantha B. Rodgers ${ }^{1}$ and Bruce A. Rivers ${ }^{1}$

\section{Correction to: Military Med Res 7, 2 (2020)}

https://doi.org/10.1186/s40779-020-0231-8

\section{Correction}

Following publication of the original article [1], the editor identified the Tables 5 and 6 are incorrect. The correct Tables 5 and 6 are as below.

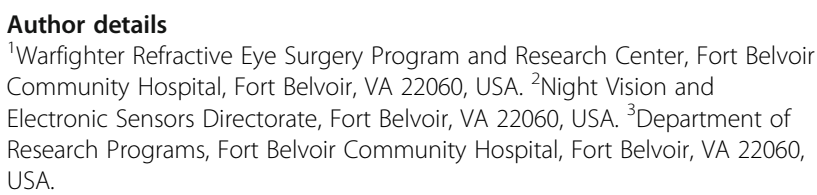

Published online: 18 October 2020

\section{Reference}

1. Ryan DS, et al. Preliminary evaluation of the Vision PERformance (MPER) simulator. Military Med Res. 2020;7:2. https://doi.org/10.1186/540779-020-0231-8.

The original article can be found online at https://doi.org/10.1186/s40779020-0231-8.

* Correspondence: denise.s.ryan ctr@mail.mil

${ }^{1}$ Warfighter Refractive Eye Surgery Program and Research Center, Fort Belvoir Community Hospital, Fort Belvoir, VA 22060, USA

Full list of author information is available at the end of the article

(c) The Author(s). 2020 Open Access This article is licensed under a Creative Commons Attribution 4.0 International License, which permits use, sharing, adaptation, distribution and reproduction in any medium or format, as long as you give appropriate credit to the original author(s) and the source, provide a link to the Creative Commons licence, and indicate if changes were made. The images or other third party material in this article are included in the article's Creative Commons licence, unless indicated otherwise in a credit line to the material. If material is not included in the article's Creative Commons licence and your intended use is not permitted by statutory regulation or exceeds the permitted use, you will need to obtain permission directly from the copyright holder. To view a copy of this licence, visit http://creativecommons.org/licenses/by/4.0/ The Creative Commons Public Domain Dedication waiver (http://creativecommons.org/publicdomain/zero/1.0/) applies to the data made available in this article, unless otherwise stated in a credit line to the data. 
Table 5 Simple (unadjusted) and multiple (adjusted) stepwise regression models for best corrected distance visual acuity logarithm of the minimum angle of resolution (logMAR), best corrected distance visual acuity manifest spherical equivalent (MSE), 25\% mesopic contrast, super vision test LogMAR and logarithm of the contrast sensitivity (logCS), and total higher order aberrations $(\mathrm{HOA})$ as predictors of average detection distance of IEDs $(n=29)$

\begin{tabular}{|c|c|c|c|c|c|c|c|}
\hline \multirow[t]{2}{*}{ Item } & \multicolumn{4}{|c|}{ Unadjusted } & \multicolumn{3}{|c|}{ Adjusted $^{a}$} \\
\hline & $\beta$ & SE & $P$ & $R^{2}$ & $\beta$ & SE & $P$ \\
\hline Best CDVA LogMAR & 3.73 & 25.00 & 0.882 & 0.001 & - & - & - \\
\hline Best CDVA MSE & 1.91 & 0.81 & 0.025 & 0.166 & 1.58 & 0.84 & 0.070 \\
\hline 25\% mesopic OU & 0.42 & 18.53 & 0.982 & $<0.0001$ & - & - & - \\
\hline Super vision visual acuity (LogMAR) & -34.24 & 24.60 & 0.175 & 0.065 & -31.28 & 23.26 & 0.190 \\
\hline Super vision contrast sensitivity (log CS) & -3.94 & 8.40 & 0.642 & 0.008 & - & - & - \\
\hline Total HOA & 0.26 & 0.33 & 0.450 & 0.022 & - & - & - \\
\hline
\end{tabular}

${ }^{a} R^{2}=0.191$; Overall $P=0.064$; "-": Not selected for inclusion in stepwise regression model; CDVA Corrected distance visual acuity, OU Both eyes

Table 6 Simple (unadjusted) and multiple (adjusted) stepwise regression models for best corrected distance visual acuity logarithm of the minimum angle of resolution (logMAR), best corrected distance visual acuity manifest spherical equivalent (MSE), 25\% mesopic contrast, super vision test LogMAR and logarithm of the contrast sensitivity (logCS), and total higher order aberrations $(\mathrm{HOA})$ as predictors of average identification distance of IEDs $(n=29)$

\begin{tabular}{|c|c|c|c|c|c|c|c|}
\hline \multirow[t]{2}{*}{ Item } & \multicolumn{4}{|c|}{ Unadjusted } & \multicolumn{3}{|c|}{ Adjusted $^{\mathrm{a}}$} \\
\hline & $\beta$ & SE & $P$ & $R^{2}$ & $\beta$ & SE & $P$ \\
\hline Best CDVA LogMAR & 5.23 & 18.77 & 0.783 & 0.003 & - & - & - \\
\hline Best CDVA MSE & 1.22 & 0.62 & 0.062 & 0.119 & 1.23 & 0.66 & 0.072 \\
\hline 25\% mesopic OU & -5.54 & 13.88 & 0.693 & 0.006 & - & - & - \\
\hline Super vision visual acuity (LogMAR) & -19.01 & 18.78 & 0.320 & 0.035 & - & - & - \\
\hline Super vision contrast sensitivity (log CS) & -4.91 & 6.27 & 0.440 & 0.021 & - & - & - \\
\hline Total HOA & 0.37 & 0.25 & 0.154 & 0.074 & - & - & - \\
\hline
\end{tabular}

${ }^{\mathrm{a}} R^{2}=0.115 ;$ " -": Not selected for inclusion in stepwise regression model; MSE Manifest spherical equivalent, CDVA Corrected distance visual acuity, OU Both eyes 